त्र

FRIEDRICH THEODOR VISCH 
FRITZ SCHLAWE

\title{
FRIEDRICH THEODOR VISCHER
}

\author{
MCMLIX \\ J.B. METZLERSCHE VERLAGSBUCHHANDLUNG \\ STUTTGART
}


ISBN 978-3-476-99134-8

ISBN 978-3-476-99133-1 (eBook)

DOI 10.1007/978-3-476-99133-1

(C) 1959 Springer-Verlag GmbH Deutschland Ursprünglich erschienen bei J. B. Metzlersche Verlagsbuchhandlung und Carl Ernst Poeschel Verlag GmbH in Stuttgart 1959 
Meiner Mutter

und meinem toten Vater 
Um einen Menschen zu verstehen, müßte man seine Doublette sein und noch dazu sein Leben gelebt baben.

Jean Paul \Jubelsenior 

$I$
Vorfabren, Eltern, Jugend I
II

Studienzeit 19

III

Vikariat und Magisterreise 43

IV

Repetentenzeit 76

V

Der junge Dozent 92

$V I$

Die große Reise 134

VII

DerWeg zum Ordinariat 144

VIII

Kampfzeiten 180

IX

Das Frankfurter Marterjabr und die

Reaktionszeit 2Is

$X$

Zürich 253

$X I$

Stuttgart 314

$X I I$

Das Alter 367

Anmerkungen - Register 


\section{VORWORT}

Wenn vor bundert Jabren irgendwo der Name Vischer genannt wurde, spitzte gleich jeder seine Obren und fragte: Was ist mit dem Vischer? Was hat er getan? Was hat er wieder gesagt? Und alsbald entspann sich dann eine rege Diskussion. Trat Vischer in der Öffentlichkeit auf, folgte ibm jeder Blick; seine Worte wurden durch ganz Deutschland kolportiert; in Büchern berief man sich auf ibn mit einer Selbstverständlichkeit, als gäbe es über ibm keine ricbtende Instanz mebr. In Nord und Süd, vor allem natürlich im Südwesten Deutscblands, bei Freund und Feind fand alles, was von Vischer ausging, ein fast erstaunliches Echo. Den Feinden war er immer zumindest ein beachtenswerter Gegner. Unzäblige aber verebrten ibn; nicht in blindem Enthusiasmus Vischers Schwächen übersehend: nein, sie scbätzten ibn trotz seiner Schwächen. Es war ein eigentümlich Belebendes um ibn. Er wirkte immer im böchsten Grade anregend, weil er den Dingen auf den Grund ging. Aber eben nicht auf eine dutzendmenschliche Weise, sondern aus tiefer Originalität des Welterlebens und Fragens. Er sprach über nichts, was nicht des Besprechens würdig war; und was er sagte, batte Hand und Fuß. Daber fanden seine Äußerungen so weitbin Widerball: man wußte, daß das, was Vischer sagte, wert war, bedacht und besprochen zu werden. Stimmte man ibm scbließlich vielleicht auch nicht bei, so füblte man sich doch von ibm um der Anregung willen bereichert; und diese starke Anregekraft verschaffte ibm seine außerordentliche Stellung im literarischen Leben der zweiten Hälfte des 19. Jabrbunderts.

Heute liegt die Gefabr nabe, Vischer samt seinen Zeitgenossen und ibrer Problemwelt zu unterschätzen. Die Sorgen des Atomzeitalters bindern sebr, die vergangenen Generationen in ibrer ganzen Bedeutung und Größe zu seben. Auf den ersten Blick scheint eben eine Zeit, die nicht vor der Atombombe zittern mußte, die noch keinen künstlichen Satelliten um die Erde kreisen sab, grundsätqlich unwichtiger, kleiner und mit allen ibren Problemen und Sorgen beinabe lächerlich gegenüber unserer Gegenwart. Aber die eigentlich menschlichen Probleme sind von Urzeit an für den Einzelnen von gleicher Bedeutung geblieben. Die Umwelt bat sich verändert, aber der Einzelne stand stets in gleich existentieller Beqiebung zu seiner jeweiligen Umwelt. Gewiß sind die Quantitäten verscbieden, aber nicht 
in dem Maße, daß die Qualität der menschlichen Probleme dadurch verändert würde: das Leben war von jeber von äußerstem Ernst, und als Maximum läßt es sich nicht irgendwie überbieten. Wer nicht jede frübere Zeit in ibrer ganzen Wichtigkeit $q^{u}$ betrachten vermag, der kann kein bistorisches Werk begreifen. Und wir wollen doch daran erinnern: das 19. Jabrbundert schritt auf allen $G e-$ bieten in ungebeuerem Maße fort. Es war ein Jabrbundert des Umbruchs. Staatsleben, Naturwissenschaft und Technik entwickelten sich in unerbörtem Wachstum. Die allgemeine Geisteshaltung erlebte eine revolutionäre Wandlung. Der aufgeklärte, von den Stürmen der französischen Revolution geweckte Einzelmensch suchte sich von den altüberkommenen Beschränkungen seines Wesens zu befreien und seinerseits an die Herrschaft zu gelangen. Er suchte das Staatsleben, er sucbte die Natur und-Gott in die Hand zu bekommen. Erkennenwollen und Herrschenwollen war dabei Eins, der Einzelne stand im Dienste philosopbischer, naturwissenschaftlicher Erkenntnissuche oder demokratischer Agitation. Was das Jabrbundert in endlosen Weben gebar, war der moderne Mensch, der nichts mebr batte als sich selbst. Er hatte Anteil am Staatsleben errungen, er hatte die Natur bezwungen und konnte glauben, Gott in die Hand bekommen zu baben. Der moderne Mensch hatte alle böchsten Ziele des früben Jabrbunderts erreicbt; aber das Menschsein war nicht ein gelöstes Problem, sondern nun erst wabres Problem geworden. Die absolute Freibeit des Einzelnen entbüllte sich als Verbannung in barte Einzelhaft; jeder batte sich an der Wand seines Kerkers seine persönliche Lösung des Problems auszurechnen oder auszumalen.

So verlief das Leben des Jabrbunderts - und eben so das Leben Vischers. Ins Dasein geworfen unter Napoleons Weltherrschaft erlebte der Knabe den Aufbruch des Volkes, empörte sich mit den Altersgenossen gegen die obrigkeitliche Unterdrückung der erwachten Masse, erbob sich dann auf den Schwingen von Hegels Pbilosopbie der Vollendung über die alten Vorstellungen von Gott, und arbeitete im Mannesalter, in der Paulskirche dafür, daß Sein Bild des freien neuen Menschen sich verwirkliche. Dem romantischen Aufschwung und der Zeit des Kampfes für die Ideale folgte die ernüchterte Einsicbt; der Greis schwieg über das, was einst böchstes Ziel gewesen war, und riet den Menschen, vor allem Mitleid qu üben. Der Jüngling kämpft, gemäß dem Alter seines Jabrbunderts, für die Befreiung der Menschbeit, der Mann schafft theoretisch für die Allgemeinbeit und praktisch in sich den neuen Menschen, und der Greis lebrt, was allein man mit seiner Freibeit anzufangen babe.

Vischers Leben hat etwas in jedem Sinne so Menschliches, daß es gerade dadurch etwas Eigentümliches ist. Als Richard Weltrich vor quei Generationen 
für die \Allgemeine Deutsche Biographies seinen Vischer-Artikel verfaßte, glaubte er noch, zur gerechten Beurteilung Vischers von seinen wissenschaftlichen Leistungen auf dem Gebiet der Ästhetik ausgehen qu müssen. Heute sind diese Leistungen ein Teil neben anderen seiner Gesamtleistung, und diese bestebt eben in seinem Dasein. Es gab größere Gelebrte im letzten Jabrbundert und es gab größere Politiker, größere Dichter: aber Vischer war alles zusammen, und mebr, und weil alle seine Lebensäußerungen aus dem Kern einer gesunden Auffassung des Daseins hervorgeben, ist sein Leben als Gesamtleistung von überragender Bedeutung. Auch zeigt die jüngste Vischer-Literatur, daß seine Problemwelt noch nicht überlebt ist. Mit merkwürdiger Gleichzeitigkeit sind die drei wichtigsten Teilgebiete bearbeitet worden; Georg Kotowski (Berlin) und Willi Oelmüller (Münster) baben in wertvollen Dissertationen den politischen Idealisten Vischer und die geistesgeschichtliche Stellung seiner ästhetischen Bestrebungen behandelt; binqu kommt meine eigene Doktorschrift über den Literarbistoriker Vischer. Auch die Veröffentlicbung des Strauß-Vischer-Briefwechsels durch Adolf Rapp, im Auftrage der Deutschen Schiller-Gesellschaft, muß bier genannt werden.

Nicht jeder begrüßst biographische Einzelheiten, die ibm in der Biographie des Genius willkommen sind, auch in der Biographie eines Anderen; so gilt leider auch von der vorliegenden Arbeit, was Johann Jacob Moser von seiner Autobiograpbie zu bericbten batte: Eben das, was einigen würdigen Männern besonders woblgefallen hat, hätten einige andere würdige Männer lieber weggelassen geseben. Allein dazu füblte ich mich nicht berechtigt. Eine genaue Lebensbeschreibung wollte ich verfassen, auch wenn sie teilweise positivistisch erschiene. Dabei befleißigte ich mich der möglichsten Schlichtheit in Form und Stil. Obne die gröBeren Zusammenbänge zu vernachlässigen, babe ich doch in jedem Zweifelsfalle lieber eine Einzeltatsache angefübrt, als ein geistesgescbichtliches Parallelfaktum; meines Erachtens ist obne die alte Andacht qum Unbedeutenden eine solche Arbeit weder $z^{u}$ schreiben noch $q^{u}$ lesen. Daß sie sich um das Individuellste kümmern darf, ist gerade das Scböne an der Biographie; sie ist die gleichsam menschlichste Form wissenschaftlichen Berichtes. An sich ist gar kein großes Objekt erforderlich. Mit Recht schrieb Leo von Kügelgen, wenn Einer nur mit Geist und Herz lebe, sei sein Leben interessant; die Berechtigung zur Biographie komme nicht nur bistorischen Personen $q^{u, ~ u n d ~ V i s c h e r ~ b a t ~ e i n e ~ L e b e n s b e s c b r e i b u n g ~ v e r d i e n t, ~}$ weil er mit Geist und Herz gelebt bat.

Im einzelnen babe ich mich von Polemik gegen die mancherlei falschen Ansichten über Vischer tunlichst ferngebalten. Belebrt baben mich aus der ganzen Vischer-Literatur allein die Scbriften von Hermann Glockner und Adolf Rapp; 


\section{VORWORT}

das Buch von Volhard bringt gute Entwicklungen, aber auch einzelne Mißgriffe. Herrn Professor Rapp danke ich zudem vielfältige liebenswürdige Belehrung im persönlichen Umgang. Auch die Herren Professoren Ackerknecht und Martini, Herr Stadtdirektor Klumpp und Herr Direktor Zeller baben mir wichtige Hinweise gegeben. Mühsam war es, den nötigen Druckzuschuß qu bekommen; sebr gütig haben mir bierbei die genannten Herren, Herr Oberregierungsrat Nägele, Herr Stadtdirektor Schumann und Herr Kulturamtsleiter Schiller gebolfen. Das Kultministerium Baden-Württemberg, die Städte Stuttgart und Ludwigsburg baben Zuschüsse geleistet. Allen genannten Herren und Institutionen danke ich biermit verbindlich.

Den Lebensunterbalt wäbrend der mebrjährigen Arbeitszeit gewäbrte mir meine berufstätige Frau.

Fritz Schlawe 